\title{
MODELAMIENTO COMPUTACIONAL DE LOS EFECTOS DEL ENVEJECIMIENTO SOBRE EL PROCESAMIENTO SINTÁCTICO EN ESPAÑOL: UN ESTUDIO MEDIANTE REDES NEURONALES
}

\author{
COMPUTATIONAL MODELLING OF THE EFFECTS \\ OF AGING ON SYNTACTIC PROCESSING IN SPANISH: \\ A STUDY USING NEURAL NETWORKS
}

\author{
CARLA BADANI SCHONEWEG \\ Universidad de Chile. Santiago, Chile. \\ cbadani@u.uchile.cl
}

\section{ALEJANDRO OSSES VECCHI}

Universidad Tecnológica de Chile. Santiago, Chile.

uglyrocks@hotmail.com

\section{BERNARDO RIFFO OCARES}

Universidad de Concepción. Concepción, Chile.

bernardo@udec.cl

\section{RESUMEN}

El presente artículo tiene como objetivo la aplicación de las redes neuronales artificiales al problema de cuantificar los efectos del envejecimiento sobre el procesamiento sintáctico de oraciones complejas en español. Los modelos de redes estudiados consiguieron establecer primero que existen dos grupos claramente diferenciados de lectores: adultos mayores y adultos jóvenes, cuyos desempeños lectores se caracterizan diferencialmente, debido a la reducción progresiva que experimenta la memoria operativa y sus efectos sobre tareas de procesamiento del lenguaje. Un segundo resultado relevante es que fue posible "envejecer" una red considerada "joven", obteniendo diferencias en una sola neurona en una capa oculta, con rendimientos similares. En un tercer resultado se aprecia el efecto de la variable sexo sobre el rendimiento lector.

Palabras clave: Envejecimiento, red neuronal, memoria operativa, edad, procesamiento sintáctico.

* Este artículo representa un desarrollo adicional del proyecto Fondecyt 1050591 del Grupo de Investigación en Psicolingüística de la Universidad de Concepción, Chile. 


\section{ABSTRACT}

The focus of this article is the application of artificial neural networks to the quantification of the effects of aging on syntactic processing of complex sentences in Spanish. The network models studied were able to establish first that there are two distinct groups of readers: older adults and younger adults, whose reading performance is characterized distinctively due to the progressive reduction in working memory and in turn its effects on reading comprehension tasks. A second important result is that it was possible to "age" a network considered "young", obtaining differences in a single neuron in a hidden layer, with similar yields. A third result shows the effect of gender on reading performance.

Keywords: Aging, neural network, working memory, age, sintactic processing.

Recibido: 28/10/2010. Aceptado: 05/04/2011

\section{INTRODUCCIÓN}

T os principales cambios de las capacidades intelectuales asociados al envejeci-

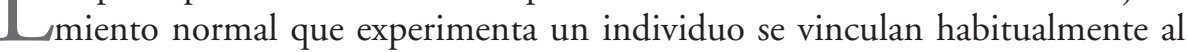
enlentecimiento en la ejecución de tareas (razonamiento, operaciones matemáticas, recuperación de información, etc.) tanto como a las pérdidas en la memoria de corto plazo. Tales hechos constituyen algunos de los efectos visibles de un proceso fisiológico general que afecta al anciano y que tiene un origen mucho más profundo. El sistema nervioso pierde eficiencia debido principalmente a causas de origen biológico, siendo una de las consecuencias de primer orden la reducción de la capacidad operativa del sistema, es decir, de la plasticidad neuronal para la interconexión entre las células nerviosas en diversos niveles con la debida intensidad y velocidad requeridas para una alta demanda o carga de procesamiento. Lo anterior se traduciría en un efecto que se manifiesta directamente durante ciertas tareas específicas y que demandan el uso de este recurso, como es el caso del procesamiento del lenguaje, que incluye la comprensión de oraciones, entre otros procesos (Denis \& Cabeza, 2008; Salthouse, 1996).

La psicolingüística experimental de corte cognitivo ha desarrollado numerosos modelos teóricos para explicar cómo los seres humanos producen y comprenden mensajes lingüísticos mediante mecanismos mentales que han sido definidos en términos de una arquitectura cognitiva. Así, es hoy de amplio consenso entre los especialistas suponer que el procesamiento del lenguaje implica unos dispositivos responsables de la percepción, registro, almacenamiento y recuperación de representaciones mentales, las que se corresponden con unidades lingüísticas en diversos niveles de organización (fonológica, léxica, sintáctica, textual). El procesamiento de oraciones, en particular, ha recibido menos atención que los procesos de nivel 
superior implicados en la comprensión del discurso. No obstante, se dispone de un número considerable de propuestas, entre las que se destacan las de Clifton, Ferreira y Frazier, entre las más conocidas (Ferreira \& Clifton, 1986; Frazier \& Rayner, 1988). En términos generales, desde la perspectiva teórica y metodológica de un enfoque cognitivo-conductual, se entiende el procesamiento como una serie de etapas que incluyen la segmentación de la señal en unidades gramaticales (parsing), la asignación de papeles temáticos y la integración sintáctico-semántica que ocurre al final de cada oración. De frecuente empleo en la investigación experimental, los métodos cronométricos han proporcionado valiosos datos empíricos, a partir de los cuales se ha llegado a establecer que el aumento en el tiempo de procesamiento constituye una evidencia del consumo de recursos cognitivos. Un incremento en el tiempo de procesamiento refleja una mayor carga de procesamiento; así, ciertos puntos de la oración reciben mayor atención, especialmente aquéllos donde se producen operaciones de integración o reanálisis (como, por ejemplo, el verbo principal luego de una oración de relativo o en oraciones ambiguas del tipo "vía muerta" (garden path)).

Desde otra perspectiva, de menor desarrollo en la psicolingüística hasta aquí, se han elaborado explicaciones computacionales del procesamiento del lenguaje. En relación con el nivel sintáctico, Tabor, Juliano \& Tanenhaus (1997) han propuesto un modelo basado en redes neuronales que incorpora el concepto de atractor, el cual explicaría los tiempos adicionales que se producen durante el procesamiento de oraciones complejas, especialmente en aquellas zonas críticas donde se realizan procesos de reanálisis. En éstas, el lector parece utilizar una estrategia de vinculación léxica o semántica de acuerdo al contexto y frecuencia de ocurrencia de las palabras para resolver ambigüedades temporales que se presentan durante la lectura. El uso de atractores definiría un espacio lingüístico en el cual los conceptos son ubicados de manera temporal mientras gravitan hacia el significado más probable, alcanzándose entonces la resolución de la ambigüedad. Este modelo de procesamiento computacional ha demostrado gran cercanía en cuanto a los resultados de los tiempos de lectura en oraciones para el inglés comparado con los resultados obtenidos por individuos reales.

El presente trabajo se propone estudiar, utilizando redes neuronales artificiales (RNA), los efectos del envejecimiento sobre el desempeño lector en comprensión de oraciones complejas del español. Los datos provienen de una serie de experimentos psicolingüísticos de comprensión de oraciones en los que, mediante técnicas cronométricas en curso, se registró el tiempo de lectura de cada palabra del material de estímulo (Riffo \& Benoit, 2007; Riffo \& Véliz, 2008; Véliz, 2004). Frente a los métodos estadísticos clásicos de análisis de datos, el empleo de una RNA se presenta como una metodología alternativa para estudiar este problema central de investigación, porque permite, a partir de registros cuantitativos, obtener patrones representativos de determinados desempeños. Estas técnicas de 
modelamiento computacional ofrecen ventajas para la problemática en cuestión, puesto que permiten que la red "aprenda" la estructura subyacente interna en los datos, sin que sea necesario definir a priori las relaciones matemáticas existentes entre las distintas variables de interés, sobre todo cuando éstas son desconocidas y previsiblemente no lineales'.

\section{LA INVESTIGACIÓN}

\subsection{Formulación del modelo}

Como se dijo antes, este estudio se propone dar cuenta del efecto que el envejecimiento tiene sobre el desempeño lingüístico en tareas de procesamiento sintáctico. Los datos cuantitativos corresponden al registro de tiempo de lectura de oraciones sintácticamente complejas obtenidos mediante técnicas cronométricas de soporte computacional. En las pruebas participaron adultos jóvenes y adultos mayores, los que leyeron series de oraciones presentadas en la pantalla de un computador con la técnica de ventana móvil palabra a palabra en modalidad autoadministrada. El procedimiento consistió en que los sujetos leían las oraciones avanzando en el proceso mediante el teclado, siendo necesario, para cada unidad léxica, un golpe de la barra espaciadora. Una vez leída una palabra, ésta quedaba oculta y se descubría la siguiente en la serie sintagmática. El computador registraba en milisegundos el tiempo transcurrido entre dos golpes de teclado, el que se considera el tiempo necesario para el procesamiento de cada palabra, según el principio de inmediatez, de larga data en la psicolingüística (Just \& Carpenter, 1980). Entre los registros se encuentra el tiempo de lectura de cada palabra (TPAL), el tiempo total de lectura de la oración (TT) y el tiempo de respuesta, correspondiente a lo que tardaba cada sujeto en responder una pregunta de comprensión situada después de cada oración leída (TR). Cuando la respuesta dada por el individuo lector fue lógica de acuerdo con la oración leída, se asignó el valor positivo, quedando establecida la variable que se denominó "respuesta coherente".

${ }^{1}$ Las RNA son sistemas distribuidos, adaptativos, los que, por lo general, aprenden de manera no lineal (Príncipe, Euliano \& Lefebvre, 2000). Tales sistemas han sido construidos a partir de muchos elementos de procesamiento diferentes. Cada uno de estos elementos recibe conexiones desde otras unidades de la misma clase o de sí mismos. Las señales que fluyen desde las conexiones son "escaladas" por medio de parámetros ajustables llamados "pesos". El procedimiento consiste en modificar el valor de la entrada por otro valor situado dentro de un rango determinado o bien, al ser multiplicado por el peso, se pondera; en otras palabras, ingresa un número dado que es modificado de acuerdo con el grado de conexión que presente esa entrada con la siguiente capa. De este modo, los elementos de procesamiento suman todas estas contribuciones y producen una salida que es una función no lineal de la suma. 
Para el propósito central de la investigación se propone un modelo que considera dos etapas (Figura 1). Una primera, llamada "de preprocesamiento", donde se establecen los parámetros que describen la complejidad de las oraciones experimentales así como las características de los individuos. En esta etapa se establecen los parámetros de entrada a la red, que corresponden a variables asociadas a la complejidad de las oraciones, las que se describen en detalle más adelante, y variables asociadas a las características del individuo lector tales como edad, sexo, capacidad de memoria operativa y el grupo etario al que pertenece, así como también variables asociadas a su desempeño lector en las tareas dadas, a saber, tiempo total de lectura (TT), tiempo de lectura por palabra (TPAL), tiempo de respuesta (TR o tiempo que demora en responder la pregunta de control) y respuesta coherente (respuesta lógica a la pregunta de control del experimento). Una segunda etapa, llamada "de procesamiento", basada en redes neuronales, es aquella en la que se obtendrían diversos patrones de comportamiento de acuerdo con los objetivos planteados en este estudio.

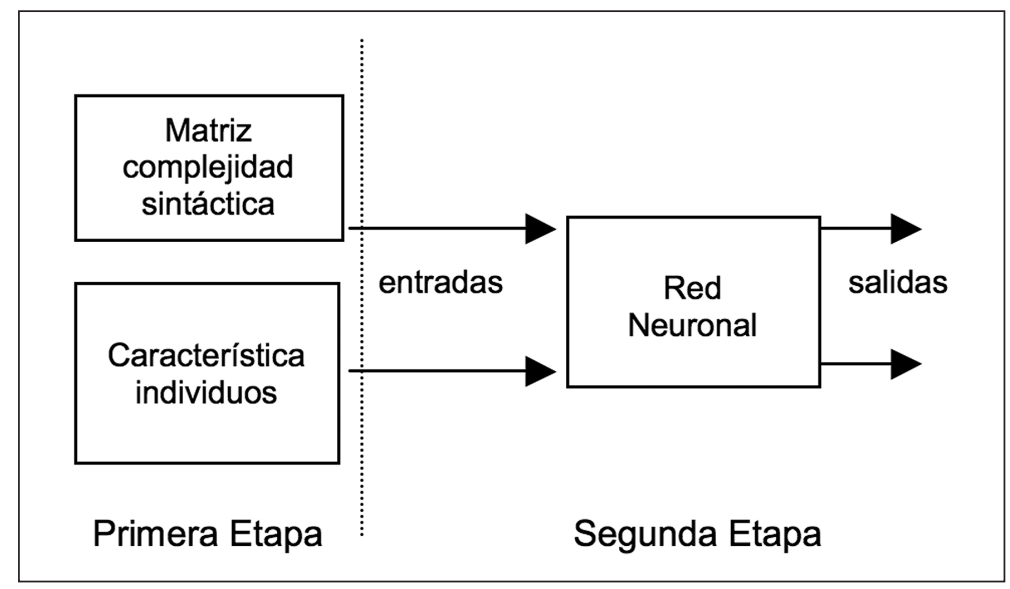

Figura 1. Modelo de procesamiento computacional.

\subsection{Hipótesis}

La hipótesis postula que el desempeño en tareas de procesamiento de oraciones complejas, medido en términos del tiempo de lectura, es altamente dependiente de la complejidad de la oración leída y de ciertos índices que caracterizan al individuo bajo observación, los cuales se relacionan principalmente con el grupo etáreo al que pertenece, tales como capacidad de memoria y edad. 


\subsection{Procesamiento de los datos}

La fase de preprocesamiento requirió establecer parámetros que dieran cuenta de la complejidad del corpus lingüístico utilizado como material de estímulo en los experimentos antes referidos. Para ello se analizaron las oraciones siguiendo los criterios de Hunt (1965), empleados también antes en el español de Chile (Véliz, 1988). Así, se segmentaron las oraciones en unidades-t constituyentes, cuyo análisis derivó en la identificación de las cláusulas presentes en cada oración y, a su vez, para cada unidad-t se estableció el nivel de profundidad de la incrustación. Posteriormente, se calcularon los índices que se presentan en la Tabla I en forma numérica.

Los índices calculados se agruparon en principales y secundarios, incorporándose a los secundarios el de posición de la cláusula incrustada y el de lógica oracional. El detalle de los índices principales es el siguiente:

1. Promedio de longitud de la unidad mínima terminal. Se calcula dividiendo el total de palabras por el total de unidades-t en cada texto (PAL/UT).

2. Promedio de longitud de la cláusula. Se obtiene dividiendo el total de palabras por el total de cláusulas (principales y subordinadas) en cada texto (PAL/CL).

3. Î́ndice de subordinación. Resulta de dividir el total de cláusulas (principales y subordinadas) por el total de unidades-t en cada texto (CL/UT).

4. Intensidad de incrustación. Mide la profundidad de la incrustación, y se obtiene calculando el nivel de incrustación promedio de las unidades-t en cada texto (II).

El conjunto de índices secundarios, también incluidos como variables de entrada en las redes bajo estudio, fueron los siguientes:

1. Promedio de cláusulas adjetivas por unidad-t. Su cálculo se realiza dividiendo en cada texto el total de cláusulas adjetivas por el total de unidades-t (CLADJ/ UT).

2. Promedio de cláusulas sustantivas por unidad-t. Se obtiene al dividir el total de cláusulas sustantivas por el total de unidades-t (CLSUS/UT).

3. Promedio de cláusulas adverbiales por unidad-t. Se calcula dividiendo el total de cláusulas adverbiales por el total de unidades-t (CLADV/UT).

4. Posición de la cláusula incrustada. (Posición central: 0; Posición derecha: 1; Posición izquierda: -1 ).

5. Lógica oracional: Lógica: 1; Ilógica: 0. 
Tabla I. Ejemplo de matriz de complejidad sintáctica para experimento 1.

\begin{tabular}{|c|c|c|c|c|c|}
\hline \multicolumn{6}{|c|}{ Índices principales } \\
\hline Oración tipo & PAL/UT & $\mathrm{PAL} / \mathrm{CL}$ & CL/UT & \multicolumn{2}{|c|}{ II } \\
\hline A & $\begin{array}{c}\text { cantidad } \\
\text { palabras/1 }\end{array}$ & $\begin{array}{c}\text { cantidad } \\
\text { palabras } / 2\end{array}$ & 2 & \multicolumn{2}{|c|}{1} \\
\hline B & $\begin{array}{c}\text { cantidad } \\
\text { palabras/1 }\end{array}$ & $\begin{array}{c}\text { cantidad } \\
\text { palabras/2 }\end{array}$ & 2 & \multicolumn{2}{|c|}{1} \\
\hline $\mathrm{C}$ & $\begin{array}{c}\text { cantidad } \\
\text { palabras/1 }\end{array}$ & $\begin{array}{c}\text { cantidad } \\
\text { palabras } / 2\end{array}$ & 2 & \multicolumn{2}{|c|}{1} \\
\hline $\mathrm{D}$ & $\begin{array}{c}\text { cantidad } \\
\text { palabras/1 }\end{array}$ & $\begin{array}{c}\text { cantidad } \\
\text { palabras } / 2\end{array}$ & 2 & \multicolumn{2}{|c|}{1} \\
\hline \multicolumn{6}{|c|}{ Índices secundarios } \\
\hline Oración tipo & CLADJ/UT & CLSUS/UT & CLADV/UT & POS & LOG \\
\hline $\mathrm{A}$ & 1 & 0 & 0 & 0 & 1 \\
\hline B & 0 & 1 & 0 & 0 & 1 \\
\hline $\mathrm{C}$ & 1 & 0 & 0 & 0 & 1 \\
\hline $\mathrm{D}$ & 0 & 1 & 0 & 0 & 1 \\
\hline
\end{tabular}

Para el presente estudio se trabajó con una base de datos de 6.559 registros de tiempo de lectura de oraciones de diversa complejidad. Estos datos se encuentran caracterizados por 30 diferentes parámetros o variables de estudio. Las redes que se entrenaron formaron parte de un conjunto de 15 redes del tipo RNA de propagación hacia adelante (feed-forward), las que presentaron configuraciones aleatorias que variaban entre 5 y 20 neuronas en la capa oculta. Una vez entrenadas, aquellas que presentaron mejor rendimiento se probaron o validaron para obtener finalmente 4 redes que modelaron los problemas que se indicaron en el artículo, a saber:

- Clasificación de un individuo según su grupo etario de acuerdo con variables asociadas a su desempeño lector tanto como a variables que lo caracterizan particularmente. Esta es una red cuya salida está dada por la variable grupo etario.

- Predicción del tiempo total empleado en la lectura de una oración. Esta es una red cuya salida corresponde al tiempo total de lectura.

- Modelamiento del tiempo total empleado en la lectura de una oración para adultos mayores a partir del modelo para adultos jóvenes envejecido. Estas son dos redes, una que se entrena con datos de adultos mayores y otra con datos de adultos jóvenes. Esta última se somete a proceso de envejecimiento y además se propone como desempeño de salida u objetivo de salida de los tiempos totales de lectura de los mayores. 


\section{RESULTADOS}

En esta sección presentamos los datos más relevantes del producto del procedimiento de análisis que, como se dijo antes, se llevó a efecto en dos etapas. En el desarrollo de esta parte se entregarán, junto con los resultados, algunos detalles de los procedimientos utilizados.

\subsection{Preprocesamiento de datos}

En esta etapa del trabajo no se obtienen todavía los resultados de salida, ya que, según lo anunciado más arriba, se efectúan aquí las operaciones de definición de parámetros. Junto con ello, es necesaria una normalización de los datos. Normalizar un conjunto de datos numéricos que conformarán el ejemplo de entrada a la red neuronal, conjunto denominado vector de entrada, consiste en someterlo a un proceso de ajuste de sus valores individuales, dividiendo cada uno por el valor más alto del conjunto. Por ejemplo, si el conjunto de datos fuera 1357 , el valor más alto correspondería a 7, de esta forma, al aplicar el proceso de normalización, el nuevo conjunto quedaría 1/7 3/7 5/7 y 1 . Este proceso se aplicó solamente a aquellas variables que alcanzaron valores superiores a 1 . Normalizar un vector de datos de entrada o salida de una red consiste en obtener otro vector cuyo valor sea la unidad, pero conservando las propiedades del mismo, en el sentido que si el valor es negativo o positivo se mantiene esa característica. Para normalizar un vector se divide éste por el valor máximo que alcanza en el rango de valores. Por ejemplo, si un vector es de valor máximo 10 , se divide el vector completo por este valor 10 , quedando de esta forma normalizado o escalado. El proceso de normalización se realizó sólo a aquellas variables de salida con rangos de valores mayores que 1 . En el caso de la predicción del tiempo total se buscó su valor máximo, el cual fue considerado en la normalización.

\subsection{Entrenamiento de las RNA}

El proceso de entrenamiento de la RNA consiste en el ajuste de todos los pesos sinápticos y valores de bias. Todas las redes entrenadas poseen una función de agregación que considera la suma ponderada de las entradas a la red con los pesos sinápticos y un factor de ajuste denominado bias. Es decir, las entradas son ponderadas por el peso sináptico (multiplicadas) y ajustadas con el valor de bias (desplazadas). Se debe considerar una determinada cantidad de capas ocultas, así como la cantidad de neuronas requeridas. También se definió qué funciones de activación serían utilizadas.

De los 6.559 vectores disponibles se utilizó para el proceso de entrenamiento la mitad de los datos (3.280 vectores de entrada). La otra parte (3.279 vectores) se 
empleó para el proceso de prueba o testeo de la red. Algunos de estos parámetros se utilizaron como variables de entrada a la red o como variables de salida, según el diseño y arquitectura de cada una.

Tabla II. Parámetros considerados en la etapa de entrenamiento de las RNA. Dependiendo el caso pueden corresponder a entradas de la red o a las salidas esperadas.

\begin{tabular}{|c|c|c|c|}
\hline Número & Parámetro & Número & Parámetro \\
\hline 1 & Edad & 16 & TPAL9 \\
\hline 2 & Sexo & 17 & TPAL10 \\
\hline 3 & Grupo etario & 18 & TPAL11 \\
\hline 4 & Memoria operativa & 19 & TPAL12 \\
\hline 5 & Memoria total dígitos & 20 & Respuesta coherente \\
\hline 6 & Memoria dígito directo & 21 & Tiempo de respuesta \\
\hline 7 & Memoria dígito inverso & 22 & Tiempo Total \\
\hline 8 & TPAL1 & 23 & PAL/UT \\
\hline 9 & TPAL2 & 24 & PAL/CL \\
\hline 10 & TPAL3 & 25 & CL/UT \\
\hline 11 & TPAL4 & 26 & Nivel de incrustación \\
\hline 12 & TPAL5 & 27 & CLADJ/UT \\
\hline 13 & TPAL6 & 28 & CLSUS/UT \\
\hline 14 & TPAL7 & 29 & Posición \\
\hline 15 & TPAL8 & 30 & Lógica oracional \\
\hline
\end{tabular}

\subsubsection{Algoritmo de entrenamiento}

Se utilizó el algoritmo de retropropagación del error (backpropagation) en su variante Levenberg-Marquardt, que es el algoritmo propuesto por la plataforma Matlab, herramienta computacional utilizada en la investigación. Para el entrenamiento de cada red se probaron aproximadamente 15 configuraciones escogidas aleatoriamente con un mínimo de 5 y un máximo de 20 neuronas por capa.

La Tabla III presenta dos redes neuronales obtenidas para los problemas de clasificación del grupo etario (red No1) y predicción del tiempo total de lectura (red No2). Las variables de entrada correspondieron en cada caso a 28, restando las variables edad y CLSUS/UT. Las configuraciones resultantes mostraron que para la red No1, 3 capas bastan para minimizar el error de validación y obtener así una clasificación correcta del grupo etario al que pertenece un individuo lector cuyos datos ingresan por primera vez a la red. Observando el error obtenido, se puede decir que de cada 100 nuevos ejemplos de entrada a la red, en más del 97\% 
de ellos la red acierta en clasificar al individuo en el grupo etario al que pertenece. Respecto de la red No2, se observa que el error obtenido es del orden de 238,56 milisegundos, lo que representa una mínima desviación respecto de los tiempos totales predichos, tiempos que superan considerablemente los tres segundos en la mayor parte de los ejemplos. Esto nos conduce a márgenes de error reducidos del orden del $8 \%$ e inferiores en la capacidad de predicción del tiempo total. La configuración óptima se obtiene con dos capas ocultas.

Tabla III. Redes Neuronales Artificiales FF encontradas óptimas para cada problema.

\begin{tabular}{|c|c|c|c|c|c|}
\hline $\begin{array}{c}\text { Red } \\
\mathbf{N}^{\circ}\end{array}$ & $\begin{array}{c}\mathbf{N}^{\circ} \text { de } \\
\text { Entradas }\end{array}$ & $\begin{array}{c}\text { Salida de } \\
\text { la Red }\end{array}$ & $\begin{array}{c}\text { Funciones de } \\
\text { Transferencia }\end{array}$ & $\begin{array}{c}\text { Error } \\
\text { Cuadrático } \\
\text { Medio } \\
\text { (MSE) }\end{array}$ & Configuración \\
\hline 1 & 28 & grupo etario & tansig - logsig & 0,0299 & $28-6-1$ \\
\hline 2 & 28 & tiempo total & $\begin{array}{l}\text { tansig - tansig } \\
- \text { logsig }\end{array}$ & 238.560 & $28-15-18-1$ \\
\hline
\end{tabular}

\subsection{Métodos utilizados para dimensionar la importancia de las variables de entrada}

Para esta parte del trabajo se consideraron 2 métodos (Montaño \& Palmer, 2003): 1) el método de Garson y 2) el análisis de sensibilidad numérica (NSA). El método de Análisis de Sensibilidad Numérica (NSA) se utilizó como principal referente en el establecimiento de jerarquías en la influencia de las entradas de la red en cada una de sus salidas. El índice NSA puede interpretarse como una pendiente que oscila entre -1 y 1 (si se ingresan los valores de las salidas normalizadas), de manera que una influencia cercana a -1 o cercana a 1 representan un efecto máximo de la entrada en la salida $k$. El método de Garson, que es a su vez un análisis basado en la magnitud de las matrices de pesos sinápticos de una RNA, presenta menor eficiencia, pero se optó por efectuar el análisis para poder comparar resultados. En todos los gráficos de análisis de sensibilidad, el eje de las abscisas (eje x) estará rotulado desde $\mathrm{x}=1 \mathrm{ax}=30$. Cada índice entero hará alusión a 1 parámetro de entrada de la red. 


\subsection{Redes de predicción}

\subsubsection{Predicción del grupo etario}

La red clasifica cada individuo en 2 categorías: adulto joven (0) o adulto mayor (1). La configuración óptima encontrada posee 6 neuronas en la capa oculta $(\mathrm{L}=$ 6). Se consideraron 28 entradas $(N=28)$ y 1 salida $(M=1)$, por lo que la configuración final es una red 28-6-1, con funciones de transferencia tangente sigmoidal y logarítmica sigmoidal para las capas ocultas y de salida, respectivamente. En la Tabla IV se resumen los parámetros de entrada y salida de la RNA.

Tabla IV. Parámetros utilizados en la RNA.

\begin{tabular}{|c|c|c|c|}
\hline Número & Parámetro & Número & Parámetro \\
\hline 2 & Género (Sexo) & 22 & Tiempo Total \\
\hline 3 & Grupo Etáreo (Target T) & 23 & PAL/UT \\
\hline 4 & Memoria operativa & 24 & PAL/CL \\
\hline 5 & Memoria total dígitos & 25 & CL/UT \\
\hline 6 & Memoria dígito directo & 26 & Nivel de incrustación \\
\hline 7 & Memoria dígito inverso & 27 & CLADJ/UT \\
\hline $8-19$ & TPAL1-12 & 28 & CLSUS/UT \\
\hline 20 & Respuesta coherente & 29 & Posición \\
\hline 21 & Tiempo de respuesta & 30 & Lógica oracional \\
\hline
\end{tabular}




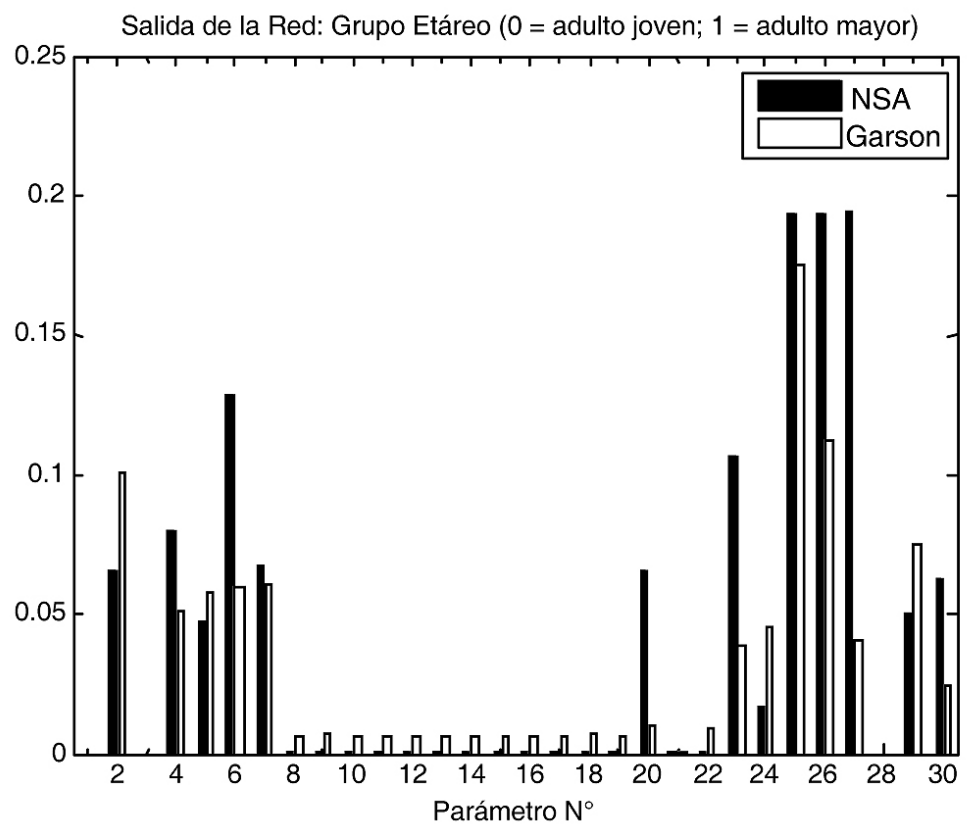

Gráfico 1. RNA FF para el Grupo Etáreo: Análisis de Sensibilidad Numérica NSA (negro) y Método de Garson (blanco). El índice NSA es presentado en valor absoluto.

Tabla V. RNA FF para el Grupo Etáreo: factores con mayor influencia de acuerdo a los métodos evaluados.

\begin{tabular}{|l|r|c|}
\hline \multicolumn{1}{|c|}{ Parámetro No / Entrada Xi } & NSA & $\begin{array}{c}\text { Método de } \\
\text { Garson [\%] }\end{array}$ \\
\hline 2. Sexo & 0,077 & 10,1 \\
\hline 4. Memoria Operativa & $-0,085$ & 5,1 \\
\hline 5. Total Dígitos & $-0,049$ & 5,8 \\
\hline 6. Dígito Directo & $-0,133$ & 6,0 \\
\hline 7. Dígito Inverso & 0,060 & 6,1 \\
\hline 23. PAL/UT & $-0,106$ & 3,9 \\
\hline 25. CL/UT & $-0,194$ & 17,6 \\
\hline 26. Nivel de Incrustación & $-0,194$ & 11,2 \\
\hline 27. CLADJ/UT & $-0,197$ & 4,1 \\
\hline 28. CLSUS/UT & 0,087 & 5,1 \\
\hline 29. Posición de la cláusula incrust. & 0,048 & 7,5 \\
\hline 30. Lógica oracional & $-0,060$ & 2,5 \\
\hline
\end{tabular}


Para la discriminación del grupo etario, el método NSA evidencia una fuerte influencia de la cantidad de cláusulas adjetivas por unidad temporal mínima (CL$\mathrm{ADJ} / \mathrm{UT}$ ), seguida por la cantidad de cláusulas (CL/UT) y el nivel de incrustación en la oración. El tiempo total de análisis, así como el tiempo asociado a cada palabra no presentan una influencia considerable en la decisión. El método de Garson destaca, en general, las mismas variables, estableciendo un orden jerárquico ligeramente diferente. Dado que la salida de la red corresponde al grupo etáreo, se aprecia que una variable relevante en la decisión corresponde a la memoria en términos generales, expresándose a través de la memoria operativa y memoria de dígitos, lo cual representa claramente una diferencia entre ambos grupos bajo análisis. Por otra parte, aspectos vinculados a la estructura propia de cada oración inciden en la decisión de clasificación etaria.

\subsubsection{Predicción del tiempo de lectura de una oración}

El problema fue modelado utilizando la característica de aproximador funcional de las RNA, es decir, la capa de salida posee sólo 1 neurona $(M=1)$, de manera que la red devuelva el tiempo que tarda un individuo en leer una oración compleja en milisegundos. La configuración óptima, encontrada empíricamente consta de 2 capas ocultas con $\mathrm{L}_{1}=15 \mathrm{y} \mathrm{L}_{2}=18$ neuronas. Se consideraron 28 parámetros de entrada $(\mathrm{N}=28)$, por lo que la configuración final es de $28-15-18-1$, con funciones de transferencia tangente sigmoidal para las capas ocultas y función lineal para la capa de salida. En la Tabla VI se resumen los parámetros de entrada y salida de la RNA.

Tabla VI. Parámetros utilizados en la RNA. La salida de la red estará asociada al tiempo total utilizado en la lectura de la oración de prueba.

\begin{tabular}{|c|c|c|c|}
\hline Número & Parámetro & Número & Parámetro \\
\hline 2 & Género (Sexo) & 22 & Tiempo total (Target T) \\
\hline 3 & Grupo etario & 23 & PAL/UT \\
\hline 4 & Memoria operativa & 24 & PAL/CL \\
\hline 5 & Total memoria dígitos & 25 & CL/UT \\
\hline 6 & Memoria dígito directo & 26 & Nivel de incrustación \\
\hline 7 & Memoria dígito inverso & 27 & CLADJ/UT \\
\hline $8-19$ & TPAL1-12 & 28 & CLSUS/UT \\
\hline 20 & Respuesta coherente & 29 & Posición \\
\hline 21 & Tiempo de respuesta & 30 & Lógica oracional \\
\hline
\end{tabular}




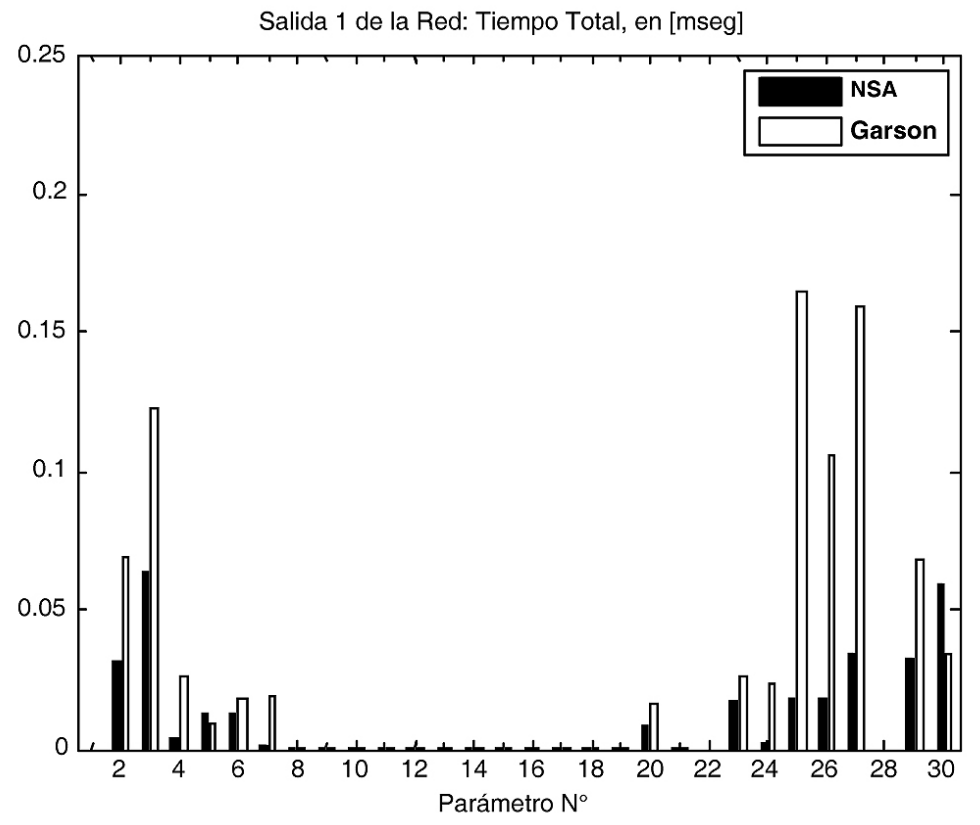

Gráfico 2. RNA FF para la predicción del tiempo total, en milisegundos: Método NSA (negro) y Método de Garson (blanco). El índice NSA es presentado en valor absoluto.

Tabla VII. RNA FF para el tiempo de análisis de una oración: factores con mayor influencia de acuerdo a los métodos evaluados.

\begin{tabular}{|l|c|c|}
\hline \multicolumn{1}{|c|}{ Parámetro No/ Entrada $X_{i}$} & NSA & $\begin{array}{c}\text { Método de } \\
\text { Garson [\%] }\end{array}$ \\
\hline 2. Sexo & 0.034 & 6.9 \\
\hline 3. Grupo Etáreo & 0.046 & 12.3 \\
\hline 4. Memoria Operativa & -0.016 & 2.7 \\
\hline 6. Memoria Dígito Directo & -0.014 & 1.8 \\
\hline 20. Respuesta Coherente & -0.025 & 1.7 \\
\hline 23. PAL/UT & 0.001 & 2.6 \\
\hline 24. PAL/CL & -0.003 & 2.3 \\
\hline 25. CL/UT & 0.018 & 16.5 \\
\hline 26. Nivel de Incrustación & 0.018 & 10.6 \\
\hline 27. CLADJ/UT & 0.017 & 16.0 \\
\hline 28. CLSUS/UT & -0.006 & 13.5 \\
\hline 29. Posición de la cláusula incrustada & 0.020 & 6.9 \\
\hline
\end{tabular}


Se puede apreciar que los factores más influyentes en la predicción del tiempo de análisis de una oración son: el grupo etáreo, el sexo, la cantidad total cláusulas y las cláusulas adjetivas por unidad temporal mínima, el nivel de incrustación y la respuesta coherente.

\subsection{Envejecimiento de una red neuronal}

Como se dijo al comienzo, parte del estudio consistió en "envejecer" una red como una forma de modelar el proceso de cambios cognitivos asociados a la edad. Existen 2 metodologías que permiten abordar el problema del envejecimiento de las RNA: 1) debilitamiento de los pesos sinápticos (disminución gradual de los valores numéricos) y 2) eliminación aleatoria de las conexiones entre algunas neuronas pertenecientes a la RNA.

Con el propósito de determinar cuál de estas 2 metodologías se aproxima más al objetivo planteado inicialmente, se trabajó sobre redes que permitieran dividir el conjunto de datos en rangos de edades, de manera que se hallara la relación que permite que a partir de una red "joven”, considerando todos sus parámetros, se llegue a una red que modele el desempeño para adultos mayores. Se escogió el caso de la predicción del tiempo de lectura de oraciones TT (tiempo total), denominado también desempeño lector. Se separaron los datos en 2 grupos, de acuerdo al grupo etario de los encuestados, por lo que se entrenaron 2 RNA, una para los encuestados jóvenes y otra para los encuestados adultos mayores. En este experimento, como el grupo etario no iba a aportar información útil para las redes a entrenar, se utilizó un parámetro de entrada menos (27 parámetros). El proceso de entrenamiento fue el mismo método empírico anteriormente explicado. La configuración óptima encontrada para cada uno de los casos es mostrada en la Tabla VIII.

Tabla VIII. Red para la predicción del tiempo total de análisis de una oración, según el rango de edad.

\begin{tabular}{|c|c|c|c|}
\hline $\begin{array}{c}\text { Configuración } \\
\mathrm{N}^{\circ}\end{array}$ & Rango de edad & $\begin{array}{c}\text { Error Cuadrático } \\
\text { Medio (MSE) }\end{array}$ & Configuración \\
\hline $1(\mathrm{AJ})$ & $19-30$ & $2,0973 \times 10^{7}$ & $27-7-13-1$ \\
\hline $\begin{array}{c}2 \\
(\mathrm{AJ} \text { envejecida) }\end{array}$ & $65-81$ & $1,0531 \times 10^{7}$ & $27-7-12-1$ \\
\hline
\end{tabular}


La Tabla VIII presenta las configuraciones resultantes para la red de adultos jóvenes y la red de adultos mayores correspondiente a la red de adultos jóvenes envejecida. Los resultados mostrados indican que ambas redes se asemejan en cuanto a su rendimiento y configuración, considerando que el error es del mismo orden de magnitud en ambas y que la configuración óptima se alcanza con dos capas ocultas que difieren en una sola neurona. En este caso, la red para adultos jóvenes, es decir aquélla entrenada y probada con datos de adultos jóvenes, presenta una neurona más que la red joven envejecida. Esta última red se entrenó con datos de jóvenes, posteriormente se envejeció y validó con datos de adultos mayores, alcanzando una neurona menos en su capa oculta. Este resultado se torna interesante, debido a que la reducción de una neurona resulta en menor cantidad de recursos en la configuración, sin embargo alcanza un rendimiento similar en cuanto a error predictivo. El margen de error es bajísimo, lo cual indica que la capacidad predictiva es alta.

El paso siguiente fue encontrar la relación entre los pesos de ambas configuraciones óptimas. Para corroborar el debilitamiento de las conexiones se determinó la media de los pesos de cada capa para ambas redes, de manera que, si consideramos 2 capas adyacentes con $N$ y $L$ neuronas, entonces la expresión utilizada para calcular la media de pesos fue:

$$
\bar{\omega}=\frac{1}{N+L} \cdot \sum_{i=1}^{N} \sum_{j=1}^{L}\left|\omega_{j i}\right|
$$

Los resultados obtenidos se muestran en la Tabla IX.

Tabla IX. Media de pesos entre capas. Se aprecia que hubo un debilitamiento en las conexiones entre redes para adultos jóvenes y adultos mayores.

\begin{tabular}{|c|c|c|}
\hline Capas: Desde - Hacia & $\begin{array}{c}\text { Media para red AJ } \\
\text { (adulto joven) }\end{array}$ & $\begin{array}{c}\text { Media para red AM } \\
\text { (adulto mayor) }\end{array}$ \\
\hline Entrada - Oculta 1 & 1,7460 & 0,7849 \\
\hline Oculta 1 - Oculta 2 & 5,0394 & 0,7558 \\
\hline Oculta 2 - Salida & 0,0422 & 0,1366 \\
\hline
\end{tabular}

De acuerdo a la Tabla IX, se puede afirmar que existe una disminución en el valor absoluto de las conexiones sinápticas de una RNA, al pasar de una configuración que modela el comportamiento para adultos jóvenes a una que modela el 
comportamiento de adultos mayores. En los pesos vinculados a la capa de salida se aprecia un fortalecimiento en la magnitud de las conexiones, pero su variación es mucho menor que el debilitamiento presentado por los otros vectores de peso. El debilitamiento de las conexiones no presenta un patrón reconocible en una primera impresión. Se requeriría una mayor cantidad de información y de diferentes redes para poder deducir alguna función que permita modelar el debilitamiento de las conexiones.

\section{DISCUSIÓN GENERAL Y CONCLUSIONES}

Se entrenaron diversas Redes Neuronales Artificiales del tipo feed-forward para la determinación del grupo etáreo y del desempeño lector medido en términos del tiempo de lectura de una oración. Todos los casos con resultados satisfactorios de acuerdo con los objetivos perseguidos con el diseño y arquitectura de cada red.

La primera red entrenada tuvo como objetivo discriminar el grupo etario al que pertenece cada individuo, sobre la base de su desempeño lector en oraciones de diversa complejidad sintáctica. Es decir, correspondió a un problema de clasificación de un individuo según su grupo etario de acuerdo con variables asociadas a su desempeño lector tanto como a variables que lo caracterizan individualmente. Para la discriminación del grupo etario no se consideró la edad como variable de entrada por la alta influencia que esta variable presenta en el problema de clasificación de grupos. Los resultados de la red permiten observar que la configuración final adoptada (28-6-1) discrimina el grupo etario en dos clases: adulto mayor y adulto joven. Las variables que ejercieron mayor influencia en el proceso predictivo de la red correspondieron a aquéllas asociadas a la complejidad sintáctica de la oración. Es el caso de las variables:

- cláusulas adjetivas por unidad-t mínima (CLADJ/UT)

- cláusulas por unidad-t (CL/UT)

- nivel de incrustación en la oración

La influencia de estas variables en la clasificación etaria parecería más determinante que el observado en investigaciones donde la atención se ha centrado más bien en los factores edad y memoria, y en la interacción de ambos (Caplan \& Waters, 1999; Carpenter, Miyake \& Just, 1994; Riffo \& Véliz, 2008; Waters \& Caplan, 1999). No es claro de qué manera puede la estructura oracional influir en la decisión del grupo etario, lo que hace pensar en una fuerte codependencia entre estas variables y las asociadas a la capacidad de memoria que es propia de cada individuo y que caracteriza sin duda a cada grupo estudiado, variable que interviene cuando el individuo procesa una oración de cierta complejidad estructural. 
El tiempo total de lectura (TT), así como el tiempo asociado a cada palabra (TPAL) no presentan una influencia considerable en la decisión, lo cual indica que no existiría en términos generales gran diferenciación del tiempo de lectura en ambos grupos. No habría un patrón temporal de lectura que caracterice a cada grupo y que permita diferenciarlos. Sin embargo, bajo el mismo concepto anterior de codependencia de variables, es factible pensar que esos tiempos similares no lo serían si apreciamos que existe una gran diferencia y un efecto importante en la decisión en términos de la memoria, expresándose ésta a través de la memoria operativa y la memoria de dígitos, lo cual representa claramente una diferencia entre ambos grupos. Es decir, tiempos similares bajo rendimientos de memoria diferentes anticipan que existirían procesos de compensación y de reestructuración del algoritmo de procesamiento, lo que permite a cada grupo lograr desempeños lectores similares con recursos de memoria distintos. Es claro que la capacidad de memoria operativa difiere en adultos mayores y adultos jóvenes, de manera que existen al menos dos grupos claramente diferenciados por la red en términos de individuos lectores, más que en términos de desempeños lectores.

La variable sexo es altamente sensible en la predicción de los rangos de edad, al combinar su efecto con otras variables asociadas tanto al individuo (memoria de dígitos, memoria operativa) como a las características de la oración (cantidad de cláusulas, por ejemplo), por lo que es posible afirmar que el ser hombre o mujer tiene una influencia no menor en el análisis de oraciones con distintos grados de complejidad sintáctica. También se puede afirmar que en el caso de existir una incrustación en una oración, la posición en que se ubica la cláusula adquiere un protagonismo mayor que el nivel de incrustación de la misma. Esto es relevante desde el punto de vista lingüístico, dado que la influencia de la ubicación de la cláusula incrustada, su posición relativa en la oración, sería un factor de complejidad mayor que el nivel de la incrustación.

En términos generales, la variable TPAL no resultó influyente en ninguna de las redes entrenadas. Podría haberse esperado que tuviera una influencia considerable en el tiempo de análisis de una oración; sin embargo, fue posible predecir este tiempo sin la variable TPAL. Esto podría llevarnos a concluir que, independiente del tiempo individual que demore en procesar un individuo una palabra, el tiempo total constituye el indicador lingüístico de desempeño lector y que el proceso de integración no se segmenta, sino que el individuo comprende cuando completa íntegramente la oración leída.

La segunda red, validada para la predicción del tiempo total empleado en procesar una oración, se modeló utilizando la característica de aproximador funcional de las RNA. Es decir, la red entregó el tiempo que tarda un individuo en analizar una oración en milisegundos. La configuración óptima, encontrada empíricamente, constó de 2 capas ocultas para lograr que la red operara a satisfacción.

Las variables que ejercieron mayor influencia en el desempeño lector corres- 
pondieron a sexo, grupo etario, la cantidad total de cláusulas y las cláusulas adjetivas por unidad temporal mínima, el nivel de incrustación y la respuesta coherente. Estas variables dan cuenta, por un lado del individuo lector y del grupo al que pertenece y por otro a la dificultad o complejidad de la oración leída. Se puede afirmar, de acuerdo con el resultado de esta red, que es posible predecir el desempeño lector en términos de tiempo de lectura total mediante las variables de entrada consideradas y que al menos el tiempo de lectura total de la oración es función del grupo etáreo al que pertenece el individuo y que las cláusulas incrustadas (cantidad, nivel y ubicación) son determinantes en su desempeño.

En las últimas dos redes, para la modelación del envejecimiento (al menos para el caso de la predicción de tiempo total de análisis oracional), el método más apropiado es aquel que plantea el debilitamiento de las conexiones sinápticas, sin embargo, no se tiene información suficiente para estudiar la función que modela el debilitamiento de los pesos sinápticos que, a partir de los datos disponibles, no cumple con una relación lineal. Las mismas configuraciones aleatorias fueron probadas paralelamente en la red para adultos jóvenes y en la red para adultos mayores. La configuración óptima para ambos casos resultó ser muy similar ya que difieren sólo en 1 neurona en la segunda capa oculta.

De esta forma, fue posible "envejecer" una red cuyo desempeño correspondía al de adultos jóvenes. De acuerdo a los resultados obtenidos, se observa que existe una disminución en el valor absoluto de las conexiones sinápticas de una RNA, al pasar de una configuración que modela el comportamiento para adultos jóvenes a una que modela el comportamiento de adultos mayores. Este efecto en la red se atribuye a un efecto de inhabilitación temporal o debilitamiento, lo que podría tener como consecuencia un aumento del tiempo de lectura por palabra o del tiempo total de lectura en la red que modela el comportamiento de adultos mayores.

$\mathrm{Al}$ analizar el error de entrenamiento en las redes de adultos mayores y jóvenes, entrenadas por separado, no se observa un patrón claro atribuible a una función que explique la dificultad inherente a los ensayos progresivos a los que la red se somete en su proceso de aprendizaje, al pasar de una capa a otra. Sin embargo, el hecho de que la red de adultos mayores presente una neurona menos en su capa oculta permite inferir que no existe necesariamente declinación en la capacidad cognitiva, dado que la red de adultos mayores converge más rápido con menos neuronas, lo que supondría un desempeño general más eficiente. Es decir, se estaría logrando mayor eficiencia en el recorrido neuronal para esta red, optimizando el tiempo de procesamiento, de manera que la carga de procesamiento sea menor y que el tiempo de procesamiento sea a su vez menor, optimizando la complejidad algorítmica. Esto nos conduciría a la hipótesis de que la capacidad de memoria de los adultos mayores se ajustaría durante el procesamiento para optimizar su rendimiento, considerando que los recursos neurológicos son inferiores a los de los adultos jóvenes. 
El signo de los resultados arrojados por el método de NSA indica si el cambio observado en la salida va en la misma dirección que el cambio provocado en la entrada bajo análisis. En este sentido, cuando se obtienen en la red que predice el tiempo total (TT) de lectura valores del índice NSA negativos para memoria operativa, esto indica que el tiempo total aumenta cuando la memoria operativa se reduce, lo cual es claro en el caso del desempeño lector para adultos mayores.

También se aprecia que el tiempo total de lectura TT aumenta cuando:

- El grupo etario es adulto mayor.

- La memoria operativa disminuye.

- El número de cláusulas totales, adjetivas y sustantivas, y el nivel de incrustación aumentan.

De esta forma, el grupo de adultos mayores presenta desempeños lectores menos eficientes y los efectos de la complejidad se manifiestan en la cantidad de cláusulas y su nivel de incrustación. Las presunciones generales que se desprenden de este trabajo, atribuibles a los efectos del envejecimiento sobre el desempeño lector, observables de las redes entrenadas, se deberían esencialmente a dos factores:

a) Un factor asociado a la declinación que supone el envejecimiento normal, asociando a éste una reducción de la capacidad de memoria general y en particular de memoria operativa. La memoria declina con la edad y presenta un efecto claro de influencia en la clasificación de grupos etáreos y de rangos de edad y en la determinación del tiempo total de lectura (Just \& Carpenter, 1992; Salthouse, 1996). De esta forma, es un factor diferenciador de la calidad de la representación que se construye durante la lectura en ambos grupos bajo estudio, existiendo dos grupos caracterizados por su desempeño: adulto mayor y adulto joven.

b) La disminución de las conexiones sinápticas que generan componentes de inhabilitación temporal o debilitamiento, sería el principal factor originador de la diferencia en desempeño lector, que tendría como consecuencia un aumento del tiempo de lectura por palabra y/o del tiempo total de lectura en adultos mayores.

El desarrollo de la investigación permitió confirmar que los factores más influyentes en el desempeño lingüístico de los adultos mayores están vinculados con la edad, la capacidad de la memoria, la complejidad de la estructura sintáctica y el sexo. Estos hallazgos confirman, en parte, lo que la literatura especializada muestra (Caplan \& Waters, 1999; Carpenter et al., 1994; Denis \& Cabeza, 2008; Kemper 
\& Greiner, 2001; Riffo \& Véliz, 2008; Véliz, 2004). Una variable no siempre considerada en las investigaciones del área, el sexo, resultó ser un poderoso elemento explicativo, lo que abre nuevas perspectivas sobre el tema. Asimismo, la fuerte dependencia que muestran los resultados respecto de la complejidad gramatical, si bien constituye un antecedente conocido en la disciplina, lleva a reconsiderar esta variable para futuros trabajos. Por último, la posibilidad de envejecer una red mediante la disminución de conexiones permite pensar, por una parte, que es posible un modelamiento del fenómeno en estudio y, por otra, que los efectos del envejecimiento guardan una estrecha relación con los cambios que tienen lugar en el sistema nervioso del ser humano, señalando al mismo tiempo una línea de investigación promisoria.

\section{REFERENCIAS}

Caplan, D. \& Waters, G. 1999. "Verbal working memory and sentence comprehension", en Behavioral and Brain Sciences 22, pp. 77-126.

Carpenter, P., Miyake, A., \& Just, M. A. 1994. "Working memory constraints in comprehension: Evidence from individual differences, aphasia, and aging". En: M. Gernsbacher (Ed.), Handbook of Psycholinguistics. San Diego, CA: Academic Press, pp. 1075-1122.

Denis, N. \& Cabeza, R. 2008. "Neuroimaging of Healthy Cognitive Aging". En: F. M. I. Craik \& T. A. Salthouse (Eds.), The Handbook of Aging and Cognition. New York: Psychology Press, pp. 1-54.

Ferreira, F. \& Clifton, Ch. 1986. "The independence of syntactic processing”, en Journal of Memory and Language 25, pp. 348-368.

Frazier, L. \& Rayner, K. 1988. "Parameterizing the language processing system: left-versus right-branching within and across languages". En J. A. Hawkens (Ed.), Explaining language universals. Oxford: Blackwell, pp. 247-279.

Hunt, K. W. 1965. Grammatical structures written at three grade levels. Research Report 3. Urbana (III): NCTE.

Just, M. A., \& Carpenter, P. A. 1980. "A theory of reading: From eye fixations to comprehension”. Psychological Review 87 (4), pp. 329-354.

Just, M. \& Carpenter, P. 1992. "A capacity theory of comprehension: Individual differences in working memory", en Psychological Review 99, pp. 122-149.

Kemper, S. \& Greiner, L. 2001. "Language Decline Across The Life Span: Findings from the Nun Study", en Psychology and Agin 16 (2), pp. 221-239.

Príncipe, J., Euliano, N. \& Lefebvre, W. 2000. Neural and Adaptative Systems: Fundamentals through Simulations. John Wiley \& Sons, Inc.

Riffo, B. \& Benoit, C. 2007. "Procesamiento de oraciones con incrustación central y derecha en adultos jóvenes y adultos mayores", en RLA 45 (1), pp. 13-31. 
Riffo B. \& Véliz, M. 2008. Informe final proyecto FONDECYT 1050591. Conicyt - Universidad de Concepción.

Salthouse, T. A. 1996. "The processing-speed theory of adult age differences in cognition”, en Psychological Review 103 (3), pp. 403-28.

Tabor, W., Juliano, C. \& Tanenhaus, M. 1997. Parsing in a Dynamical System: An Attractor-based Account of the Interaction of Lexical and Structural Constraints in Sentence Processing. New York: University of Rochester, Rochester.

Véliz, M. 1988. "Evaluación de la madurez sintáctica en el discurso escrito", en RLA 26, pp. 105-141.

Véliz, M. 2004. "Procesamiento de estructuras sintácticas complejas en adultos mayores y adultos jóvenes”, en Estudios Filológicos 39, pp. 65-81.

Waters, G. \& Caplan, D. 1999. "Verbal working memory capacity and on-line sentence processing efficiency in the elderly". En S. Kemper \& R. Kliegel (Eds). Constraints on language: Aging, grammar and memory. Boston: Academic Publishers, pp. 107-135. 